\title{
Immunological responses to respiratory syncytial virus infection in infancy
}

\author{
R L Smyth, J N Fletcher, H M Thomas, C A Hart
}

\begin{abstract}
Objectives-To determine whether there is evidence of immunological responses in infants with respiratory syncytial virus (RSV) bronchiolitis by measuring inflammatory mediators in peripheral blood and, if found, whether these related to the severity of illness.

Patients and methods-Blood was taken from 94 children with RSV infection during the acute episode and 10 or more days later when the child was well. Control serum samples were obtained from well children of similar ages. Serum samples were assayed for mediators of lymphocyte activity (interleukin-4 (IL-4), soluble interleukin-2 receptor (sCD25), soluble intercellular adhesion molecule-1 (sICAM-1), eosinophil activity (eosinophil cationic protein) and neutrophil activity (myeloperoxidase). Symptoms were assessed as very mild (coryza only), mild (symptoms of lower respiratory tract infection), moderate (requiring nasogastric or intravenous fluids), and severe (requiring oxygen or ventilation).

Results-IL-4 concentrations were at the lower limits of detection of the assay. The concentrations of $\mathrm{sCD}-25$ were greater in samples from patients with acute illness than from convalescent patients and both were greater than in control samples. sICAM-1 concentrations were similar in samples from patients with acute illness and convalescent patients, but both were greater than in samples from controls. Eosinophil cationic protein concentrations were lower in samples from patients with acute illness than in those from convalescent patients; there was no difference between samples from convalescent and control patients. Myeloperoxidase concentrations were similar in all samples. There was no correlation between the severity of infection and the concentrations of any inflammatory mediators.

Conclusions-There is evidence of an inflammatory response in the peripheral blood of infants with acute bronchiolitis which may affect lymphocytes and eosinophils, but an association between this response and the severity of illness was not shown here.

(Arch Dis Child 1997;76:210-214)
\end{abstract}

Keywords: respiratory syncytial virus; immunological responses; bronchiolitis.
Respiratory syncytial virus (RSV) bronchiolitis is one of the most important causes of death and morbidity in infants less than 6 months of age. ${ }^{1} \mathrm{RSV}$ infections are prevalent in young children and almost all have serological evidence of infection by the age of 2 years. ${ }^{1}$ The proportion of those infected who develop symptoms is unknown, however. Studies of urban populations ${ }^{2}$ have estimated that 25/ 1000 infants will develop RSV bronchiolitis severe enough to require hospital admission and about $3 \%$ of these develop respiratory failure and require ventilation. Although there is evidence that factors such as pre-existing cardiopulmonary disease, ${ }^{3}$ prematurity, ${ }^{4}$ parental smoking, ${ }^{5}$ and atopy ${ }^{6}{ }^{7}$ may predispose to severe bronchiolitis and death from RSV infection, the mechanisms by which this occurs are not understood.

Young children vaccinated with RSV inactivated with formalin developed augmented lower respiratory tract disease during subsequent natural infection. Studies at necropsy of such children showed pathological changes which included the infiltration of lymphocytes and eosinophils into the lungs. ${ }^{8}$ In addition, children who had more severe bronchiolitis when subsequently infected with the natural virus showed an increased blood eosinophilia relative to controls. ${ }^{9}$ This concept of RSV bronchiolitis as an immunopathological disorder has been supported by experimental studies in $\mathrm{BALB} / \mathrm{c}$ mice, ${ }^{10}{ }^{11}$ where the passive transfer of CD4+ and CD8+ cell lines into animals infected with RSV caused them to become ill and lose weight. Both cell lines reduced lung titres of RSV (CD4+ more than CD8+) but increased the severity of their lung pathology and recipients of CD4+ cells developed a striking pulmonary eosinophilia. There is further evidence from the murine model that RSV antigens can selectively activate $\mathrm{T}$ lymphocyte subsets. ${ }^{12}{ }^{13}$ Alwan et al have shown that whole inactivated virus and recombinant vaccinia expressing the major surface glycoprotein of RSV preferentially activate lymphocytes that express type 2 cytokine profiles. ${ }^{12}$ In previous work by the same group the vaccinia recombinant expressing the major surface glycoprotein was shown to produce a response in the bronchoalveolar lavage fluid which included eosinophils. ${ }^{14}$

We aimed to investigate the immunological responses to RSV infection in infants by measuring the serum concentrations of inflammatory mediators known to be produced during immunological responses. We evaluated the lymphocyte responses by measuring concen- 
trations of interleukin-4 (IL-4), soluble interleukin-2 receptor (sCD-25), and intercellular adhesion molecule-1 (ICAM-1). IL-4 is an important type 2 cytokine. ${ }^{15}$ In children with asthma, serum concentrations of sCD25 have been shown to be higher than in controls ${ }^{16}$ and to correlate with asthma severity. ${ }^{17}$ Soluble ICAM-1 (sICAM-1) mediates various cell-cell interactions in inflammation by binding to leucocyte integrin adhesion receptors ${ }^{18}$ and has been implicated in the inflammatory process, resulting in epithelial cell injury in asthma. To assess the eosinophil response we measured the concentrations of eosinophil cationic protein, a cytotoxic protein contained in the granules of eosinophils, which has been studied previously in infants with RSV infection. ${ }^{19}$

A previous clinical study has challenged the view that excessive lymphocyte mediated cytotoxic activity is principally responsible for the pathology of RSV bronchiolitis and suggested that neutrophils play an important part. ${ }^{20} \mathrm{We}$ therefore measured myeloperoxidase, which is a neutrophil primary granule product. ${ }^{21}$ Serum concentrations of myeloperoxidase have been found to be increased in children with acute bronchiolitis. ${ }^{22}$

Two hypotheses were investigated. Firstly, that the concentrations of the inflammatory mediators would be increased during acute bronchiolitis and, secondly, that the concentrations of inflammatory mediators would vary depending on the severity of the child's illness.

\section{Patients and methods}

Ninety four infants less than 1 year of age, admitted to the Royal Liverpool Children's Hospital between January 1991 and March 1992, were recruited to the study. All had symptoms of a coryzal illness with or without lower respiratory tract symptoms and signs. Respiratory syncytial virus infection was diagnosed initially by indirect immunofluorescence on nasopharyngeal aspirates, but was confirmed in all patients by a reverse transcriptase polymerase chain reaction ${ }^{23}$ using specific primers for the nucleoprotein gene. ${ }^{24} \mathrm{~A}$ sample of clotted blood was obtained at the time of the child's admission to hospital with RSV infection (acute sample). A further convalescent serum sample was taken at least 10 days later (range 10-153 days) when the child had recovered from the acute illness. All clotted blood samples were separated by centrifugation and immediately stored at $-20^{\circ} \mathrm{C}$. Controls were well children less than 1 year of age who had a routine blood sample taken as part of their assessment before an operation.

During the child's admission for acute illness clinical details were recorded by interviewing the parents and examining the case notes. This information enabled the children to be classified subsequently by one of us (RLS), who was unaware of the study results, into one of four groups according to the severity of the child's illness. The illness was assessed as being very mild (coryza only), mild (symptoms of lower respiratory tract infection), moderate (requiring nasogastric or intravenous fluids), and severe (requiring oxygen or ventilation). The severity groups to which patients were assigned represented their clinical status during the most severe period of their illness.

IL-4, sICAM-1, and soluble CD25 (sCD25) were measured in the acute and convalescent serum samples using commercial ELISA kits (Medgenix Diagnostics, Fleurus, Belgium). Serum samples were diluted as necessary with the buffer supplied and duplicate assays were performed on each. Assays were read using a Multiskan MCC/34o MkII ELISA reader (Flow Laboratories) at $450 \mathrm{~nm}$. Cytokine concentrations were calculated from the standard graph of duplicate standards included on each plate and the mean value for each sample was calculated. Eosinophil cationic protein and myeloperoxidase concentrations were measured by commercial radioimmunoassay kits (Pharmacia, Uppsala, Sweden) as described previously. ${ }^{25}{ }^{26}$ Bound radioactivity was measured by gamma counting and the concentrations of eosinophil cationic protein and myeloperoxidase in each serum sample were interpolated from the graph of the standards included.

Differences between sICAM-1, sCD-25, eosinophil cationic protein, and myeloperoxidase concentrations in the serum samples from infants during the acute and convalescent phases of their illness and from control infants were analysed by Student's $t$ test using SPSS statistical software (SPSS Inc). Student's $t$ test was also used to compare the concentrations of the inflammatory markers in the acute serum samples of children with moderate and severe disease with those in the mild and very mild groups. Comparisons of serum samples of the same patient during the acute illness and during convalescence were by the paired sample $t$ test, whereas those between different patients were by independent $t$ test.

This study was performed as part of a larger study to investigate the pathogenesis of RSV bronchiolitis. ${ }^{27}$ Ethical committee approval was obtained from the local paediatric research ethics committee.

\section{Results}

Of the 94 infants studied there were six, 33, 24, and 26 , respectively, in the very mild, mild, moderate, and severe disease groups. In five infants there was insufficient clinical information to accurately classify the severity of disease. Measurements of IL- 4 in patients during the acute and convalescent phases and at all severities were at the lower limits of detection of the assay system.

Concentrations of sCD-25, sICAM-1, eosinophil cationic protein, and myeloperoxidase were measured in paired samples from 81,80 , 89 , and 87 infants, respectively, with bronchiolitis. The sCD-25 concentrations were significantly greater during the acute illness than during convalescence $(p<0.01)$. The sCD-25 concentrations in infants with bronchiolitis during both the acute disease and convalescence were significantly greater than in the controls ( $p<0.01$ ) (fig 1). The sICAM-1 concentrations measured during acute illness were not significantly different from those measured 


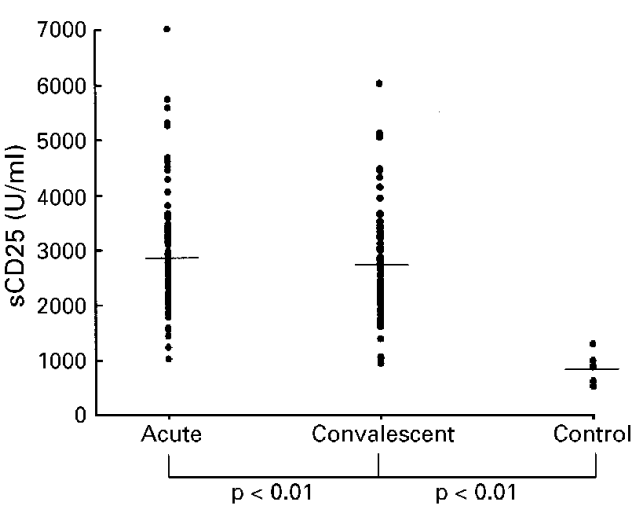

Figure 1 Serum concentrations of $s C D-25$ in patients during acute illness, during convalescence, and in controls. Horizontal lines indicate mean values. Each patient is represented by an individual symbol.

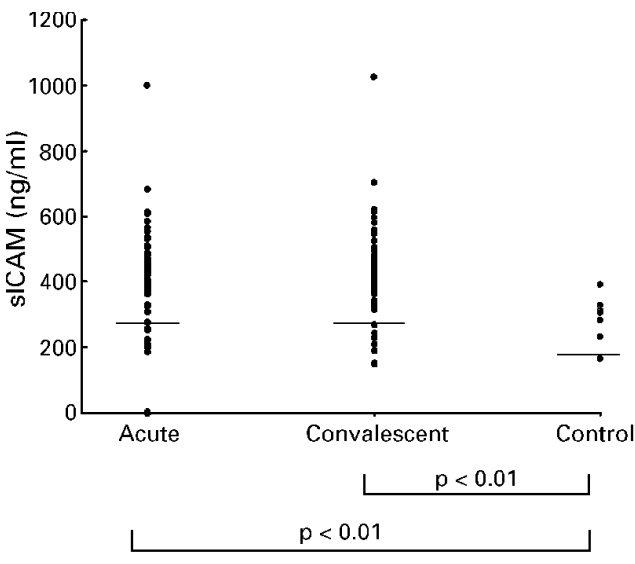

Figure 2 Serum concentrations of sICAM-1 in patients during acute illness, during convalescence, and in controls. Horizontal lines indicate mean values. Each patient is represented by an individual symbol.

during convalescence. The sICAM-1 concentrations in infants with bronchiolitis at both times were, however, significantly greater than in controls $(p<0.01)$ (fig 2$)$. The eosinophil cationic protein concentrations were significantly lower during acute illness than during convalescence $(p<0.01)$, but there was no difference between infants with bronchiolitis at either time point and the controls (fig 3). To assess whether this relation was found for those convalescent samples taken more than 30 days after acute infection, we repeated the analysis on this subgroup and found that eosinophil cationic protein concentrations in serum samples taken during acute disease were lower than in samples taken after 30 days $(\mathrm{p}<0.01)$. Myeloperoxidase concentrations were similar in infants at both time points and in controls (fig 4). There was no significant difference between concentrations of sCD-25, sICAM-1, eosinophil cationic protein, and myeloperoxidase measured during acute illness in infants in the moderate and severe groups compared with those in the mild and very mild groups (data not shown).

\section{Discussion}

We have shown that inflammatory mediators produced during a lymphocyte response are increased during acute infection in children

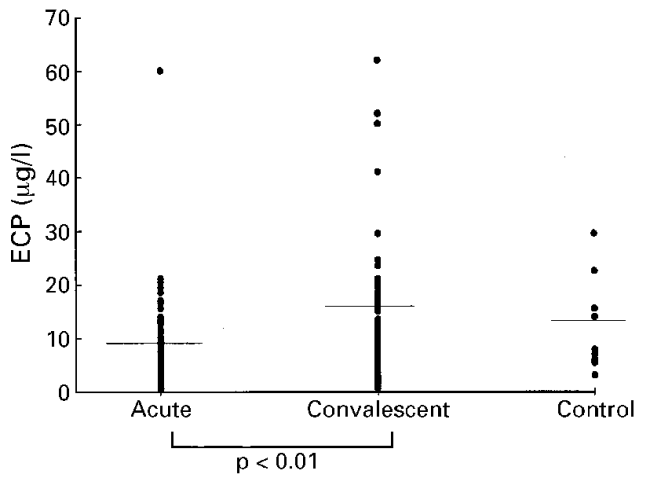

Figure 3 Serum concentrations of eosinophil cationic protein (ECP) in patients during acute illness, during convalescence, and in controls. Horizontal lines indicate mean values. Each patient is represented by an individual symbol.

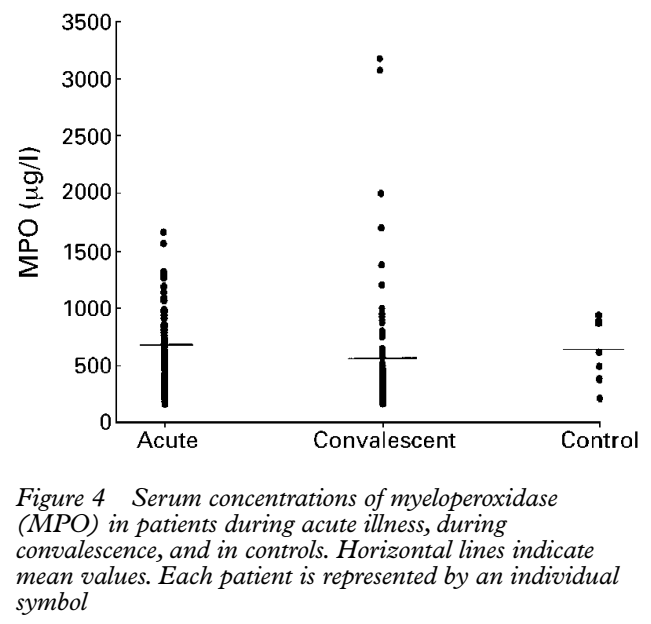

with bronchiolitis compared with controls. In addition, sCD-25, but not sICAM-1, concentrations were increased during acute infection compared with those concentrations measured when the child had recovered. Concentrations of eosinophil cationic protein, a toxic product of activated eosinophils, ${ }^{28}$ were, however, lower in infants with bronchiolitis during the acute illness than when they had recovered clinically. Concentrations of myeloperoxidase, an enzyme released by activated neutrophils, were similar in children with bronchiolitis and controls.

Although, to our knowledge, the mediators of lymphocyte activation have not been studied extensively in children with bronchiolitis, they have been studied in asthma, a disorder with many clinical and epidemiological similarities to bronchiolitis. ${ }^{5}{ }^{6}$ Respiratory viruses are often associated with exacerbations of asthma ${ }^{29}$ and activated $\mathrm{T}$ lymphocytes and eosinophils are thought to play a central part ${ }^{30} 31$ in the immunopathology of asthma. In bronchoalveolar lavage fluid from patients with asthma, concentrations of sCD25 correlated with the percentages of eosinophils, ${ }^{32}$ suggesting that $\mathrm{T}$ cell activation within the bronchial tree and eosinophil infiltration are intimately associated. Bentley et al have shown that the epithelial expression of sICAM-1 was more common in patients with asthma than in control subjects. ${ }^{33}$ In a primate model of asthma, Wagner et $a 3^{34}$ showed that eosinophil infiltration in the airway 
was reduced by monoclonal antibodies to sICAM-1. It was disappointing that the measurement of IL-4 responses was not more informative, but we would be cautious about interpreting the presence of a type 1 or type 2 lymphocyte response on the basis of these data.

The roles of eosinophil cationic protein and myeloperoxidase, inflammatory mediators produced by eosinophils and neutrophils, respectively, have been extensively studied in patients with asthma ${ }^{2835}$ and bronchiolitis. ${ }^{1936}$ In a study in Sweden, Sigurs et al measured eosinophil cationic protein and myeloperoxidase in serum samples from 19 infants with RSV bronchiolitis and then again one and six months later. ${ }^{22}$ Serum eosinophil cationic protein concentrations did not differ significantly between acute infection and the follow up visits, but serum myeloperoxidase concentrations were significantly higher during acute infection than one month later. Eosinophil cationic protein/albumin ratios in nasal secretions from 34 children with RSV bronchiolitis were significantly lower than those measured six months later, however.

One of the problems with examining inflammatory mediators circulating in the serum is that these measurements may not provide an accurate reflection of the immunological responses occurring in the affected organ. Sigurs et al did not find any correlation between eosinophil cationic protein concentrations in serum and nasal secretions. ${ }^{22}$ There are, however, potential sources of error in collecting material such as nasopharyngeal aspirate and bronchoalveolar lavage fluid from the airways, including difficulties in quantifying the secretions and the measured substances and correcting for any dilution. ${ }^{22}$ The correlation between serum sCD-25 concentrations and objective clinical measures of airway obstruction in children with asthma provides some reassurance that serum concentrations of sCD-25 reflect disease activity. ${ }^{17}$

It was therefore interesting in this context that $\mathrm{sCD} 25$ concentrations were higher in infants during acute infection than at follow up. The converse result for eosinophil cationic protein, where concentrations were higher after the acute infection, is also interesting. This is not due to a peaking of eosinophil cationic protein concentrations shortly after illness, as the relation still held when the comparison was made just for those samples from convalescent patients taken more than 30 days after acute infection. There is more than one possible explanation. As has been previously suggested by the work of Garofolo et $a l^{19}$ it may be that there is a huge influx of eosinophils, with eosinophil cationic protein release locally in the airways, but this is not reflected in high serum eosinophil cationic protein concentrations. An alternative explanation ${ }^{22}$ is that RSV bronchiolitis gives rise to a long standing inflammatory reaction in the airways and that eosinophil activation increases after acute infection. This may explain why some children subsequently develop recurrent wheezing.

When the severity of RSV bronchiolitis was examined, we could not show a correlation between this and the concentrations of any of the inflammatory mediators. Only six of the 94 infants studied had no lower respiratory tract symptoms and signs, however, indicating very mild disease. It is possible that if we had studied a group of infants who were more representative of the pattern of RSV disease in the community, such differences may have been evident. We are planning to investigate this by further studies which include infants with RSV infection who do not require admission to hospital. We are also planning to examine samples from the upper and lower airways.

This study of a large group of infants with RSV infection provides further evidence of an immunopathological response to this infection involving lymphocytes and eosinophils, but not neutrophils.

This study was supported by a grant from the Foundation for the Study of Infant Deaths.

1 Kim HW, Arrobio JO, Brandt CD, et al. Epidemiology of respiratory syncytial virus infection in Washington DC I. Importance of the virus in different respiratory tract disease syndromes and temporal distribution of infection. $\mathrm{Am} 7$ Epidemiol 1973;98:355-64.

2 Stott EJ, Taylor G. Respiratory syncytial virus. Brief review. Arch Virol 1985;84:1-52.

3 Groothius JR, Gutierrez KM, Lauer BA. Respiratory syncytial virus infection in children with bronchopulmonary dysplasia. Pediatrics 1988;82:199-203.

plasia. Pediatrics 1988;82:199-203.
4 Parrott RH, Kim HW, Arrobio JO, et al. Epidemiology of Parrott $\mathrm{RH}$, Kim HW, Arrobio JO, et al. Epidemiology of
respiratory syncytial virus infection in Washington DC II. Am ₹ Epidemiol 1973;98:289-300.

5 McConnochie KM, Roghmann KJ. Wheezing at 8 and 13 McConnochie KM, Roghmann KJ. Wheezing at 8 and 13
years: changing importance of bronchiolitis and passive smoking. Pediatr Pulmonol 1989;6:138-46.

6 Rooney JC, Williams HE. The relationship between proved viral bronchiolitis and subsequent wheezing. $\mathcal{F}$ Pediatr 1971;79:744-7.

7 Laing I, Reidel F, Yap PL, Simpson H. Atopy predisposing to acute bronchiolitis during an epidemic of respiratory syncytial virus. $B M \mathcal{F} 1982 ; 284: 1070-2$.

8 Kim HW, Canchola JG, Brandt CD, et al. Respiratory syncytial virus disease in infants despite prior administration of antigenic inactivated vaccine. Am f Epidemiol 1969;89:42234.

9 Chin J, Magoffin RL, Shearer LA, Schieble JH, Lennette EN. Field evaluation of a respiratory syncytial virus vaccine and a trivalent parainfluenza virus vaccine in a pediatric population. Am $\mathcal{f}$ Epidemiol 1969;89:449-63.

10 Alwan WH, Record FM, Openshaw PJM. CD4 ${ }^{+} \mathrm{T}$ cells clear virus but augment disease in mice infected with respiclear virus but augment disease in mice infected with respiT cells. Clin Exp Immunol 1992;88:527-36.

11 Openshaw PJM, Clarke SL, Record FM. Pulmonary eosinophilic response to respiratory syncytial virus infection in mice sensitized to the major surface glycoprotein G. Int Immunol 1992;4:493-500.

12 Alwan WH, Kozlowska WJ, Openshaw PJM. Distinct types of lung disease caused by functional subsets of antiviral T cells. $\mathcal{F}$ Exp Med 1994;179:81-9.

13 Graham BS, Henderson GS, Tang YW, et al. Priming immunization determines $\mathrm{T}$ helper cytokine mRNA expression patterns in lungs of mice challenged with respiratory syncytial virus. F Immunol 1993;151:2032-40.

14 Openshaw PJ, Clarke SL, Record FM. Pulmonary eosinophilic response to respiratory syncytial virus infection in mice sensitized to the major surface glycoprotein G. Int Immunol 1992;4:493-500.

15 Graham BS. Pathogenesis of respiratory syncytial virus vaccine-augmented pathology. Am $\mathcal{f}$ Respir Crit Care Med 1995;152:S63-6.

16 Schmitt M, Niggemann B, Kleinau I, Nasert S, Kapp A, Wahn U. Lymphocyte subsets, sIL2-R and sICAM-1 in blood during allergen challenge tests in asthmatic children. Pediatr Allergy Immunol 1993;4:208-13.

17 Hoeger PH, Niggemann B, Ganschow R, Dammann C, Haeuser G. Serum levels of sCD23 and sCD25 in children with asthma and in healthy controls. Allergy 1994;49:21721

18 Seth R, Raymond FD, Makgoba MW. Circulating ICAM-1 isoforms: diagnostic prospects for inflammatory and immune disorders. Lancet 1991;338:83-4.

19 Garafalo R, Kimpen JLL, Welliver RC, Ogra PL. Eosinophil degranulation in the respiratory tract during naturally acquired respiratory syncytial virus infection. $\mathcal{F}$ Pediatr 1992;120:28-32.

20 Everard ML, Swarbrick A, Wrightham M, et al. Analysis of cells obtained by bronchial lavage of infants with 
respiratory syncytial virus infection. Arch Dis Child 1994;71:428-32.

21 Regelmann WE, Siefferman CM, Herron JM, Elliott GR, Clawson CC, Gray BH. Sputum peroxidase activity correlates with the severity of lung disease in cystic fibrosis. Pediatr Pulmonol 1995;19:1-9.

22 Sigurs N, Bjarnason R, Sigurbergsson F. Eosinophil cationic protein in nasal secretion and in serum and myeloperoxidase in serum in respiratory syncytial viral bronchiolitis: relationship to asthma and atopy. Acta Pediatr 1994;83 151-5.

23 Cane PA, Pringle CR. Molecular epidemiology of respiratory syncytial virus: rapid identification of subgroup A lineages. F Virol Methods 1992;40:297-306.

24 Cane PA, Pringle CR. Respiratory syncytial virus heterogeneity during an epidemic: analysis by limited nucleotide sequencing (SH gene) and restriction mapping (N gene). $\mathcal{F}$ Gen Virol 1991;72:349-57.

25 Peterson C, Enander I, Nystrand J, Anderson A, Nilsson L, Venge P. Radioimmunoassay of human eosinophil cationic protein (ESP) by an improved method. Establishment of
normal levels in serum and turnover in vivo. Clin Exp normal levels in serum

26 Olofsson T, Olsson I, Venge P, Elgefors B. Serum myeloperoxidase and lactoferrin in neutropenia. Scand $\mathcal{F}$ Haemato 1977; 18:73-80

27 Cane PA, Thomas HM, Simpson AF, Evans JE, Hart CA Pringle CR. Analysis of human serological immun response to a variable region of the attachment $(\mathrm{G})$ protein of respiratory syncytial virus during primary infection. $\mathcal{F}$ Med Virol 1996;48:253-61.
28 Carlson M, Hakansson L, Kampe M, Stalenheim G, Peterson C, Venge P. Degranulation of eosinophils from pollenatopic patients with asthma is increased during pollen season. F Allergy Clin Immunol 1992;89:131-9.

29 Pattemore PK, Johnston SL, Bardin PG. Viruses as precipitants of asthma symptoms I. Epidemiology. Clin Exp Allergy 1992;22:325-36.

30 Azzawi M, Bradley B, Jeffery PK, et al. Identification of activated $\mathrm{T}$ lymphocytes and eosinophils in bronchial biopsies in stable atopic asthma. Am Rev Respir Dis 1990;142:140713.

31 Frigas E, Gleich J. The eosinophil and the pathophysiology of asthma. F Allergy Clin Immunol 1986;77:527-37.

32 Park CS, Lee SM, Uh ST, et al. Soluble interleukin-2 receptor and cellular profiles in bronchoalveolar lavage fluid from patients with bronchial asthma. $\mathcal{F}$ Allergy Clin Immunol 1993;91:623-33.

33 Bentley AM, Durham SR, Kay AB. Comparison of the immunopathology of extrinsic, intrinsic and occupational asthma. F Invest Allergy Clin Immunol 1994;4:222-32.

34 Wegner CD, Gundel RH, Reilly P, Haynes N, Letts LG, Rothlein R. Intercellular adhesion molecule-1 (ICAM-1) in the pathogenesis of asthma. Science 1990;247:456-9.

$35 \mathrm{Kay} \mathrm{AB}$. Asthma and inflammation. $\mathcal{F}$ Allergy Clin Immunol 1991;17:893-910.

36 Colocho Zelaya EA, Orvell C, Strannegard O. Eosinophil cationic protein in nasopharyngeal secretions and serum of infants infected with respiratory syncytial virus. Pediatr Allergy Immunol 1994;5:100-6.

Parents in the anaesthetic room

Probably most paediatricians would opt for parents being present at the induction of anaesthesia. Nevertheless the issue is not as clear cut as some might think; some children may be more anxious with parents present and some anaesthetists find it unnerving. A randomised trial at Yale University (Anesthesiology 1996;84:1060-7) showed no difference in behavioural response with parents present or absent but serum cortisols were lower in the presence of the parents in three cirucumstances; when the child was over 4 years, when the child was shy or inhibited, and when the parents showed low anxiety levels. Younger children tended to have a higher serum cortisol with parents there.

This study involved a single paediatric anaesthetist at a tertiary centre; all the children took part in a preoperative programme of information, explanation, and acclimatisation and none was given premedication. The results may not be relevant to other groups of children. No mention is made in this report of parents who refused to take part in the trial. There must surely have been such parents and their absence from the trial could have influenced the results.

That the presence of parents is necessarily beneficial can not be taken to be self evident. Each case is different and dependent on the child, the parents, and the anaesthetist. Nevertheless a parent friendly bias on the part of hospital staff can be no bad thing.

ARCHIVIST 